\title{
Abortion and its legalization: An overview of the opinion of doctors in Colombo South Teaching Hospital, Sri Lanka
}

\author{
Dinethri RPA ${ }^{1}$, Roshanthan $\mathrm{N}^{1}$, Perera MAPA ${ }^{1}$, Wasana $\mathrm{WDO}^{1}$, Perera AABS ${ }^{1}$, Vidanapathirana $\mathrm{M}^{2 *}$, Wijewardena \\ $\mathrm{K}^{3}$, Siddhisena KAP
}

\begin{abstract}
Introduction: According to Sri Lankan law, the only indication for abortion is when the life of the mother is in danger. Abortion is the third commonest cause for maternal mortality in Sri Lanka. Therefore, to make a change in current legal situation of abortion in Sri Lanka, it is important to assess the opinion on abortion especially from doctors, because they deal directly with maternal and child health. Method: According to random sampling method, a self-administered questionnaire was given to 207 doctors at the Teaching Hospital Colombo South, Sri Lanka. Results: Almost all (97\%) agreed to perform abortion when mothers' life is in danger and $76 \%$ agreed when mother's health in danger. As overall opinion 57\% agreed in special medical conditions such as Anencephaly, Down syndrome, Thalassemia major and hemophilia. Further, 68\% agreed with abortion when 'Rape' and 'Incest', however, when rape presents as the condition disagreement of Muslims was statistically significant ( $\mathrm{p}<0.05)$. Most (74\%) disagreed with social conditions such as contraceptive failure, family health in danger, family with low income and higher number of children. When contraceptive failure or family health in danger presents as the condition, the disagreement of less than 10 years of experience doctors was statistically significant $(\mathrm{p}<0.05)$. Majority (69\%) agreed for legalization of abortion in Sri Lanka for more conditions. Regarding advantages, 66\% agreed and $65 \%$ reported that there will be disadvantages after legalization of abortion. Conclusion: In addition to, when mother's life is in danger, majority agreed to include medical conditions such as when mother's health is in danger and four other special medical conditions, and legal situations such as rape and incest. However, majority disagreed on social conditions.
\end{abstract}

Key words: legalization of abortion, Sri Lanka, opinion of doctors, experience, education,

\section{Full paper}

\section{Introduction}

Abortion is defined as the spontaneous or induced termination of pregnancy before viability [1]. According to Sri Lankan law, miscarriage is the termination of pregnancy before its natural expulsion [2]. In Sri Lanka, therapeutic abortion can be performed only on one indication: when mother's life is in danger [2].

${ }^{1}$ Undergraduate, ${ }^{2}$ Professor, ${ }^{3}$ Senior Professor, Faculty of Medical Sciences, University of Sri Jayewardenepura, Sri Lanka, ${ }^{4}$ Professor Emeritus, Department of Demography, University of Colombo, Sri Lanka

*Corresponding author: Vidanapathirana M, email: mudithavidana@sjp.ac.lk Tel: 0094772988227, Fax: 0094112801480
In the developed world, abortion has been one of the safest procedures in medicine when allowed by local law. 'Safe Abortions' do not cause either long term mental or physical problems [3] and the WHO recommends that this same level of safe and legal abortions be available to all women globally [4].

Morbidity and mortality due to 'Unsafe Abortions' are a global issue. Unsafe abortion is defined as a procedure for terminating an unintended pregnancy carried out either by persons lacking the necessary skills or in an environment that does not conformed to minimal medical standards or both [5]. An estimated 44 million abortions are performed globally each year, with about $50 \%$ of those performed unsafely [6]. Unsafe abortions, however, result in approximately 5 million hospital admissions and 47,000 maternal deaths per year globally [7] and of them $13 \%$ are due to unsafe abortions [8].

In many parts of the world there is prominent public controversy over the moral, ethical, and legal issues of abortion. Those who are against abortion generally state that an embryo or fetus is a human with the right 
to life and may compare abortion to murder. Those who support abortion rights emphasize a woman's right to decide matters concerning her own body as well as emphasizing human rights generally [9].

Abortion is legalized for many indications other than when mother's life is in danger in many countries. For instance in India, abortion is legal up to 28 weeks of pregnancy under the Medical Termination of Pregnancy (MTP) Act and there are more indications for abortion other than mother's life in danger such as mother's health in danger, pregnancy following rape or incest, and foetal anomalies [10]. It is estimated that of the 210 million pregnancies that occur globally each year, $10 \%$ are due to ineffective use of a contraceptive methods [11] and contraceptive failure also has been identified as an indication for termination in India.

Abortion is generally illegal in Sri Lanka under the Section 303 of the Penal Code. Section 303 of the Penal Code provides that anyone voluntarily causing a woman with child to miscarry is subject up to three years imprisonment and/or payment of a fine, unless the miscarriage was caused in good faith in order to save the life of the mother [2]. Therefore, in Sri Lanka, current legislation allows pregnancy termination only when required to save the life of the mother [2].

In 1973, the Medico-Legal Society of Sri Lanka recommended that the law should be liberalized to allow abortions to be performed to prevent grave injury to the physical and mental health of the mother, in cases where pregnancy resulted from rape or incest, and in cases where there was substantial risk that the child, if born, would suffer from severe physical or mental abnormalities [11]. No legislative action, however, resulted from these recommendations. In 2011, the Sri Lanka College of Obstetricians and Gynaecologists, in collaboration with relevant partners, presented a draft petition to the relevant authorities appealing to liberalize the abortion law in cases of pregnancy following incestuous rape or lethal congenital anomalies [1], but failed.

Despite rigid statutory provisions, Sri Lankan women of higher socio-economic status who desire to terminate their pregnancies find little or no difficulty in getting it done. Women from middle and lower socio-income layer, however, are often resort to abortions performed by "back-door abortionists" under primitive and unhygienic conditions [11]. Local health officials estimated that the 2014 maternal mortality rate was 32.03 deaths per 100,000 live births, of them, $12.5 \%$ related to unsafe abortions [13]. Today, in Sri Lanka, abortion is the third commonest cause for maternal death [13]. Moreover, the studies estimated that there are around 1000 abortions performed daily in Sri Lanka [14].

Unsafe abortions cause lot of morbidity and mortality of the mothers whilst the two previous attempts to liberalize abortion policy also failed. That reiterates why we should perform research on this problem in Sri Lanka. Further, the results of various research done in other countries reveal that the maternal death rates have been reduced with liberalization of abortion. Therefore, this study was conducted to overview the opinion of doctors in Colombo South Teaching Hospital regarding abortion and its legalization and to describe the associations between opinion of doctors' regarding abortion and some selected demographic factors of doctors.

\section{Methodology}

Doctors were selected as the study population, because they are more aware of abortion and its complications. Colombo South Teaching Hospital (CSTH) was selected as the study setting because it has variety of doctors from all three ethnic groups who had graduated from different universities, different age groups, different years of work experience and with different levels of education in their medical carriers. The study population included Consultants, Senior Registrars, Registrars, Senior House Officers, Residential House Officers and House Officers of CSTH.

A descriptive cross sectional study was conducted. The participants were selected by random sampling method. After obtaining the ethical clearance and the permission from the Director, CSTH, selfadministered questionnaire was given to participants, after obtaining informed written consent. Data collection was conducted for 12 weeks. Considering the expected proportion of doctors favoring termination of pregnancy for Down syndrome as 0.84 (84\%) [15], the sample size was determined as 207. Data were analyzed using the IBM SPSS 21. The responses "strongly agree' and 'agree" were considered together as 'agreed' and "strongly disagree' and 'disagree' were considered together as 'disagreed'.

The Study instrument was a self- administered questionnaire which consisted of 20 questions. Pretesting of the questionnaire was done on 10 doctors who work at Sri Jayewardenepura General Hospital. 
Rape is defined as "committing sexual intercourse without consent under the listed circumstances in the section 363 of the Penal Code of Sri Lanka". [16] Incest means "Whoever has sexual intercourse with another who stands towards him in any of the enumerated degrees of relationships as described in the section 364A of the penal code of Sri Lank". [16]

\section{Results}

The socio-demographic characteristics of the 207 participants such as age, sex, marital status, ethnicity, religion, designation, years of experience, country of graduation are shown in Table 1.

Table 1: Frequency distribution of socio-demographic characteristics of respondents

\begin{tabular}{|c|c|c|}
\hline & Socio-demographic factors & $\begin{array}{l}\text { Total }(\mathrm{N}=207) \\
\%(\mathrm{n})\end{array}$ \\
\hline \multirow[t]{2}{*}{ Sex } & Male & $50(103)$ \\
\hline & Female & $50(104)$ \\
\hline \multirow[t]{3}{*}{ Age } & $<35$ years & $59(122)$ \\
\hline & $35-45$ years & $25(52)$ \\
\hline & $>45 y e a r s$ & $16(33)$ \\
\hline \multirow[t]{3}{*}{ Race } & Sinhalese & $73(152)$ \\
\hline & Tamil & $21(43)$ \\
\hline & Muslim & $06(12)$ \\
\hline \multirow[t]{2}{*}{ Marital status } & Married & $69(142)$ \\
\hline & Unmarried & $31(65)$ \\
\hline \multirow[t]{5}{*}{ Religion } & Buddhist & $71(146)$ \\
\hline & Hindu & $17(35)$ \\
\hline & Islam & $05(11)$ \\
\hline & Catholic & $06(13)$ \\
\hline & Atheist & $01(02)$ \\
\hline \multirow[t]{4}{*}{ Designation } & Consultant & $05(10)$ \\
\hline & Registrar or Senior Registrar & $12(25)$ \\
\hline & Medical Officer (MO) & $61(126)$ \\
\hline & House officer & $22(46)$ \\
\hline \multirow[t]{3}{*}{ Experience } & Less than 5 years & $50(104)$ \\
\hline & 5-10 Years & $24(50)$ \\
\hline & More than 10 year & $26(53)$ \\
\hline \multirow[t]{2}{*}{ Graduated from } & Sri Lankan University & $92(191)$ \\
\hline & Foreign University & $08(16)$ \\
\hline
\end{tabular}

The only existing legal condition for abortion in Sri Lanka is when mother's life is in danger. The three potential situations considered for liberalization of abortion were medical, legal and social situations.
Table 2 shows the overall opinion of participants for legalization of abortion for other situations in Sri Lanka. 
Table 2: Overall opinion for legalization of abortion for other situations (medical, legal and social) in Sri Lanka

\begin{tabular}{lccccc}
\hline & $\begin{array}{c}\text { Strongly Agree } \\
\%(\mathrm{n})\end{array}$ & $\begin{array}{c}\text { Agree } \\
\%(\mathrm{n})\end{array}$ & $\begin{array}{c}\text { No idea } \\
\%(\mathrm{n})\end{array}$ & $\begin{array}{c}\text { Disagree } \\
\%(\mathrm{n})\end{array}$ & $\begin{array}{c}\text { Strongly Disagree } \\
\%(\mathrm{n})\end{array}$ \\
\hline Legalization & $30(62)$ & $39(81)$ & $09(19)$ & $15(30)$ & $07(14)$ \\
\hline \hline
\end{tabular}

Of the participants, 69\% $(n=143)$ agreed (including strongly agree and agree) and $22 \%(n=44)$ disagreed (including strongly disagree and disagree) for the legalization of abortion for other situations in Sri Lanka.
Table 3 depicts the opinion on performing abortion in different situations. Agree and strongly agree were considered as 'Agree' and strongly disagree and disagree as 'Disagree',

Table 3: Overall opinion of legalization of abortion in different situations

\begin{tabular}{lll}
\hline \hline Factor & $\begin{array}{l}\text { Agree } \\
\%(\mathbf{n})\end{array}$ & $\begin{array}{c}\text { Disagree } \\
\boldsymbol{\%}(\mathbf{n})\end{array}$ \\
\hline $\begin{array}{l}\text { Existing law: Mother's Life is in danger } \\
\text { Medical conditions }\end{array} \quad \% 7(200)$ & $03(05)$ \\
$\quad$ Mother's Health is in danger & & $13(26)$ \\
$\quad$ Other Special medical conditions & $76(157)$ & $29(60)$ \\
Legal conditions & $57(117)$ & $18(38)$ \\
Social conditions & $68(141)$ & $74(152)$ \\
\hline \hline
\end{tabular}

Almost all (97\%, n=200) agreed with existing indication of abortion 'when mother's Life is in danger'. Majority agreed to legalize abortion on medical conditions $(76 \%$ for mother's health in danger and $57 \%$ for other special medical conditions) and legal conditions $(68 \% \mathrm{t})$. Majority $(74 \%, \mathrm{n}=152)$ disagreed with abortion on social indications.

The medical conditions for liberalization of abortion included, when mother's health is in danger and four other special medical conditions. The opinion on legalization of abortion when 'mother's health is in danger'; majority (76\%) agreed, however, showed no significant association with the socio-demographic factors $(p>0.05)$. The four special medical conditions considered for legalization were Anencephaly, Down syndrome, Haemophilia and Thalassemia major. Though majority agreed $(57 \%)$ for abortion on above special medical conditions, opinion of the participants on each of those special medical situations showed no significant association with socio-demographic factors $(\mathrm{p}>0.05)$.

The two considered legal situations were rape and incest. Table 4 shows the opinion on legalization of abortion on rape and their associations with sociodemographic factors.

When all the parameters were considered, except the participants who were Muslims, more than about $67 \%$ agreed with abortion if pregnancy is resulted by a 'Rape'. Regarding the factor of ethnicity, the difference seen in the distribution was statistically significant $(\mathrm{p}=0.010<0.05)$. However, the opinion in legalization of abortion on legal situations such as 'Incest', about $2 / 3^{\text {rd }}$ of respondents agreed with abortion and there was no significant association between their opinion and socio demographic factors $(\mathrm{p}>0.05)$. 
Table 4: Legalization of abortion on legal situations such as Rape

\begin{tabular}{|c|c|c|c|c|c|}
\hline Factor & & Agree \% (n) & Disagree \% (n) & $\chi^{2}(\mathrm{df})$ & $\mathrm{P}$ \\
\hline \multirow[t]{2}{*}{ Sex } & Male & $71(72)$ & $29(30)$ & \multirow{2}{*}{$0.309(1)$} & \multirow{2}{*}{$0.578>0.05$} \\
\hline & Female & $67(69)$ & $33(34)$ & & \\
\hline \multirow[t]{3}{*}{ Ethnicity } & Sinhala & $70(105)$ & $30(45)$ & \multirow{3}{*}{$4.432(2)$} & \multirow{3}{*}{$0.010<0.05$} \\
\hline & Tamil & $72(31)$ & $28(12)$ & & \\
\hline & Muslim & $42(05)$ & $58(07)$ & & \\
\hline \multirow[t]{2}{*}{ Designation } & Postgraduate & $74(26)$ & $26(09)$ & \multirow{2}{*}{$0.596(1)$} & \multirow{2}{*}{$0.440>0.05$} \\
\hline & Non-postgraduate & 68 (115) & $32(55)$ & & \\
\hline \multirow[t]{2}{*}{ Experience } & $<10$ years & 68 (104) & $32(49)$ & \multirow{2}{*}{$0.183(1)$} & \multirow{2}{*}{$0.669>0.05$} \\
\hline & $\geq 10$ years & $71(37)$ & $29(16)$ & & \\
\hline
\end{tabular}

The three social conditions considered for income and high number of children'. The opinion on legalization of abortion were 'contraceptive failure', legalization of abortion on contraceptive failure and their associations with socio-demographic factors are 'family health in danger' and 'family with low shown in Table 5.

Table 5: Legalization of abortion on social situations such as contraceptive failure

\begin{tabular}{|c|c|c|c|c|c|}
\hline & Factor & Agree $\%(\mathrm{n})$ & Disagree \% (n) & $\chi^{2}(\mathrm{df})$ & $\mathrm{P}$ \\
\hline \multirow[t]{2}{*}{ Sex } & Male & $20(20)$ & $80(82)$ & \multirow[b]{2}{*}{$0.540(1)$} & \multirow[b]{2}{*}{$0.463>0.05$} \\
\hline & Female & $16(16)$ & $84(86)$ & & \\
\hline \multirow[t]{3}{*}{ Ethnicity } & Sinhala & $15(23)$ & $85(126)$ & \multirow{3}{*}{$4.332(2)$} & \multirow{3}{*}{$0.115>0.05$} \\
\hline & Tamil & $28(12)$ & $72(31)$ & & \\
\hline & Muslim & $08(01)$ & $92(11)$ & & \\
\hline \multirow[t]{2}{*}{ Designation } & Postgraduate & $15(05)$ & $85(29)$ & \multirow[b]{2}{*}{$0.243(1)$} & \multirow[b]{2}{*}{$0.622>0.05$} \\
\hline & Non-postgraduate & $18(31)$ & 82 (139) & & \\
\hline \multirow[t]{2}{*}{ Experience } & $<10$ years & $14(21)$ & $86(130)$ & \multirow{2}{*}{$5.593(1)$} & \multirow{2}{*}{$0.018<0.05$} \\
\hline & $\geq 10$ years & $28(15)$ & $72(38)$ & & \\
\hline
\end{tabular}

Most disagreed with abortion in contraceptive failure. However, $72 \%(n=38)$ of participants with more than 10 years of experience and $86 \%(n=130)$ of less than 10 years of experience disagreed about performing abortion in contraceptive failure and this difference was statistically significant $\quad(\mathrm{df}=5.593$, $\mathrm{p}=0.018<0.05)$.

Similarly, majority disagreed with abortion on 'when family members' health is in danger'. Further, 73\% $(n=37)$ of more than 10 years of experience and $89 \%$ 
$(n=134)$ of less than 10 years of experience disagreed and this difference was statistically significant $(\mathrm{df}=6.429, \mathrm{p}=0.011<0.05)$.

Moreover, most disagreed with abortion when the 'Family with low income and higher number of children'. When ethnicity was concerned, 88\% $(n=135)$ of Sinhalese and $100 \%$ of Muslims disagreed. However, $77 \%(n=27)$ of postgraduates and $90 \%(n=155)$ of non-postgraduates disagreed and this difference was statistically significant $(\mathrm{df}=4.610$, $\mathrm{p}=0.032<0.05)$.

Table 6 clearly shows the opinion on identified advantages and disadvantages of legalization of abortion in Sri Lanka.

Table 6: Opinion on the identified advantages and disadvantages of legalization of abortion

\begin{tabular}{lccc}
\hline \hline Factor & Agree & No idea & Disagree \\
& $\%(\mathrm{n})$ & $\%(\mathrm{n})$ & $\%(\mathrm{n})$ \\
\hline Advantages & $66(137)$ & $08(17)$ & $26(53)$ \\
$\quad$ Reduce Maternal mortality rate & $75(154)$ & $08(17)$ & $17(34)$ \\
Reduce Unwanted Pregnancy & $68(138)$ & $16(36)$ & $19(40)$ \\
& & & $07(14)$ \\
Disadvantages & $65(135)$ & $09(19)$ & $36(74)$ \\
Misuse of legal abortion & $81(167)$ & $22(46)$ & \\
$\quad$ Reduce usage of contraceptives & $37(77)$ & & \\
\hline \hline
\end{tabular}

When all the parameters were considered, $66 \%$ $(n=137)$ agreed that there will be advantages if abortion is legalized in Sri Lanka. However, 65\% $(n=135)$ agreed that there will be disadvantages also. Further, none of the advantages or disadvantages had statistically significant association $(p>0.05)$ with socio-demographic factors.

\section{Discussion}

The laws related to abortion_vary greatly around the world. In some contexts, abortion is legally based on medical indications such as mother's life or health in danger, foetal anomalies, legal indications such as rape and incest, and socioeconomic factors such as contraceptive failure, health status of the family and high number of children in a family with low income [17]. By the year 2008, 40\% of the world's women had access to legally sanctioned 'Safe abortions' "without restriction as to reason" [18]. However, in Sri Lanka, pregnancy termination is restricted by law and social norms [19] and despite significant number of morbidity and mortality, legal abortions are confined only to one indication; when mother's life in danger [2].
In this study, it was revealed that the majority of the participants agreed to legalize abortion in some identified medical and legal situations, but disagreed to legalize abortion on identified social indications.

The sample of the study represented variety of doctors from all three ethnic groups, graduated from different universities, different age groups, and different years of experience and different stages of education level in their medical carriers.

According to the current study, when considering special medical conditions such as Down syndrome, Anencephaly, Hemophilia and Thalassemia major, majority had positive attitude towards abortion in all four conditions. However, in a study done on the views of Iranian physicians about terminating pregnancy due to Thalassemia major, Hemophilia, and Down's syndrome revealed that the majority of physicians were in agreement with abortion for Thalassemia major $(91 \%)$ and Down's syndrome (79\%), but opposed to abortion for hemophilia (more than 50\%) [20].

Legal conditions considered in the study were rape and incest. Nearly more than 2/3rd agreed with abortion when rape is presented as the condition. 
Similarly, a study done by the Argentine Society of Critical Care to survey the opinion of critical care providers in Argentina about abortion, 89\% supported abortion in cases of rape [21]. In the current study, males $(71 \%)$ and females $(67 \%)$ had similar opinion regarding rape. When considered the ethnicity, Sinhalese (70\%) and Tamils (72\%) agreed with abortion in case of rape, however, majority of Muslims (58\%) disagreed and this association was statistically significant $(\mathrm{p}=0.01<0.05) \quad$ (Table 4). Majority of Muslims disagreed and this may be due to their differences in cultural and religious background from other major ethnic groups, Sinhalese and Tamils. Further, in Muslim religious environment, performing an abortion is an antireligious activity ("Haraam") [22].

When incest was considered as the underlying situation, about $2 / 3^{\text {rd }}$ of respondents agreed with abortion and there was no significant association ( $>0.05$ ) between their opinion and socio demographic factors. Regarding the factor ethnicity which showed significant association in the condition of rape $(p<0.05)$, has not become significant in incest ( $>0.05$ ). Even though these two conditions have different terminology, both of these situations are almost the same. Rape means committing sexual intercourse without the consent of a woman in circumstances as described in the section 363 of the penal code of Sri Lanka whilst 'Incest' means a graver type of 'rape' where the perpetrator possesses some relationship to the victim as described in the section 364 of the penal code of Sri Lanka [16]. Therefore, this difference of opinion might be due to poor knowledge among participants about the term incest.

When the social situations such as contraceptive failure, other family members' health in danger and 'family with low income and higher number of children' were considered, according to Table 3 , the majority $(74 \%, \mathrm{n}=152)$ disagreed with legalization of abortion in such social conditions.

When factor of contraceptive failure was considered, as shown in Table 5 , both males $(80 \%, \mathrm{n}=82)$ and females $(84 \%, n=86)$ almost equally disagreed in legalization of abortion following contraceptive failure. Further, $72 \%(n=38)$ of more than 10 year experience and $86 \%(\mathrm{n}=130)$ of less than 10 year experience doctors disagreed to perform abortion on 'contraceptive failure' and this association was statistically significant $(p=0.018<0.05)$. Therefore, when contraceptive failure presents as the condition, the disagreement of less than 10 years of experience doctors was statistically significant $(\mathrm{p}<0.05)$.
Similarly, when the factor 'Other family members' health in danger' was considered, the disagreement of less than 10 years of experience doctors was statistically significant $(\mathrm{p}=0.011<0.05)$.

Both males and females, of Sinhala $(89 \%, \mathrm{n}=135)$ Tamil (81\%, $\mathrm{n}=35)$ and Muslim $(100 \%, \mathrm{n}=12)$ participants disagreed with seeking abortion when 'family with low income and higher number of children' (Table 3). Further, 77\% $(n=27)$ of postgraduates and $90 \%(n=155)$ of non-postgraduates disagreed to perform abortion on 'family with low income and higher number of children' and this association was statistically significant $(p=0.032<0.05)$. Therefore, when 'family with low income and higher number of children' presents as the condition, the disagreement of non-postgraduate doctors was statistically significant $(\mathrm{p}<0.05)$. A study done in 2004, among Sri Lankan women seeking termination of pregnancy revealed that majority used induced abortion as a family planning method and presence of a young child in the family was the commonest reason for termination [23].

According to another research carried out in 2014 on people who go to providers of pregnancy termination, revealed that the most common reasons for abortion were "pregnancy too soon after previous delivery", "no more children desired" or "curtailment of opportunity for foreign employment". The researchers state that the need for abortion of them are not currently being met by reproductive health programs in Sri Lanka, and it is important that they should be given special attention in the future [30].

Majority $(66 \%, \mathrm{n}=137)$ agreed on the fact that there will be advantages after legalization of abortion in Sri Lanka. Almost $3 / 4^{\text {th }}$ of respondents $(75 \%, n=154)$ agreed that maternal mortality rate will be reduced and $2 / 3$ of respondents $(68 \%, n=138)$ believed that unwanted pregnancies would be reduced, if abortion is legalized in Sri Lanka (Table 2). A study done in Nepal observed a significant decline in the rate of serious abortion morbidity after liberalization of abortion in 2002 [24]. Another study done in Romania, South Africa and Bangladesh showed that there was marked reduction in maternal mortality following legalization of abortion [25]. Further, after legalization of abortion, the occurrence of mental illnesses, mental stress and family problems that develop due to unsafe abortions are expected to be reduced [26].

When the opinion on disadvantages of legalization of abortion was considered (Table 2), 65\% ( $\mathrm{n}=135)$ agreed that there will be disadvantages. More than 
$4 / 5^{\text {th }}(81 \%, n=167)$ agreed that there will be misuse of legal abortion and about $1 / 3^{\text {rd }}(37 \%, n=77)$ agreed that there will be reduce(d) usage of oral contraceptive methods, if abortion is legalized in Sri Lanka. Therefore, the Sri Lankan culture may be affected and prostitution, abuse of females and other forms of sexual crime could be more prevalent. However, none of the advantages or disadvantages had statistically significant association with sociodemographic factors $(\mathrm{p}>0.05)$.

According to the overall opinion on legalization of abortion, almost all (97\%, $\mathrm{n}=200)$ agreed with abortion when mother's life is in danger and more than $3 / 4^{\text {th }}(76 \%, n=157)$ agreed with abortion when the mother's health is in danger (Table 2). Similarly, a study conducted to survey the opinion of critical care providers in Argentina about abortion, 77\% supported abortion when women's mental health is at risk [20].

Majority of $(57 \%, \mathrm{n}=117)$ doctors agreed with legalization of abortion in special medical conditions especially genetic diseases such as Down syndrome, Anencephaly, Thalassemia major and Haemophilia (Table 3). However, a similar study done to survey the opinion of critical care providers in Argentina about abortion, all most all $(95 \%)$ supported abortion in cases of congenital defects [20]. On Contrary, in the current study, quite a significant number $(29 \%$, $\mathrm{n}=60$ ) disagreed to legalize abortion in such genetic conditions (Table 3). Therefore, until legalization, the introduction of family screening for genetic diseases, genetic counseling and promoting contraceptive methods would be useful to reduce the incidence of such genetic disease conditions. Accordingly, in Sri Lanka, up to 2008, rates of abortions had been declining with improved access to education regarding family planning and birth control [27].

According to the overall opinion, more than $2 / 3$ of doctors $(68 \%, \mathrm{n}=141)$ agreed with abortion in legal conditions such as rape and incest. However, almost $2 / 3^{\text {rd }}$ of doctors $(74 \%, n=152)$ disagreed with abortion in social situations such as contraceptive failure, other family members' health in danger and family with low income and high number of children (Table 3). This suggests that there is a strong belief among the participants that these social conditions are preventable by medical strategies. Further, this disagreement on social conditions had significant associations with the participants' 'lack of experience' and 'less postgraduate qualifications. When contraceptive failure or family health in danger presents as the condition, the disagreement of less than 10 years of experience doctors was statistically significant $(\mathrm{p}<0.035)$. When family with low income and higher number of children presents as the condition the disagreement of non-postgraduate doctors was statistically significant $(\mathrm{p}<0.05)$.

Finally, more than $2 / 3^{\text {rd }}(69 \%, n=143)$ agreed in legalising abortion in Sri Lanka for more conditions other than mother's life in danger (Table 2).

\section{Conclusions}

Majority of the participants agreed for legalization of abortion in Sri Lanka for more medical and legal circumstances in addition to when mother's life is in danger. On the contrary, majority disagreed with abortion in social situations. However, the experience and further postgraduate education have significantly reduced the disagreement on social conditions. Nearly equal number of doctors responded that there will be both advantages and disadvantages after legalization of abortion in Sri Lanka. Therefore, until the laws for legalization of abortion for more conditions are enacted in Sri Lanka, family planning services and counseling should be offered especially in premarital, pre-pregnancy and post-pregnancy periods in order to reduce the number of unsafe abortions.

\section{Acknowledgments}

We express our heartfelt gratitude to, Dr. Chamara Senarathna, Department of community medicine, Faculty of Medical Sciences, University of Sri Jayewardenepura for being one of former supervisors, Prof. S. Sivayogan, Dr. WAA Wijayasiri, Dr. S. Prathapan, Dr. S Goonawardene for the assistance provided, doctors of Sri Jayewardenepura General Hospital for the participation in the pre-test and all the participant doctors in Colombo South Teaching hospital for participation in our research.

\section{References}

1. Mosby Medical dictionary $8^{\text {th }}$ Edition.

2. Section-303, Penal code, Democratic Socialist Republic of Sri Lanka.

3. Lohr, PA, Fjerstad, M, Desilva, U, Lyus, R. "Abortion". BMJ 2014;348: f7553. doi:10. 1136/ bmj.f7553

4. World Health Organization (2012). Safe abortion: technical and policy guidance for health systems (PDF) (2nd Ed.). Geneva: World Health Organization. p. 8. ISBN 9789241548434.

5. Unsafe abortion, Global and regional estimates of the incidence of unsafe abortion and associated mortality in $2008,6^{\text {th }}$ end, WHO, ISBN 9789241501118 , http://apps.who. int/iris/ bitstream/10665/44529/ 1/9789241501118_eng.pdf, accessed on 14.01.2016

6. Sedgh, G.; Singh, S.; Shah, I. H.; Åhman, E.; Henshaw, S. K.; Bankole, A.. "Induced abortion: Incidence and trends worldwide from 1995 to 2008" 
(PDF). The Lancet. 2012; 379(9816): 625-632. doi:10.1016/S0140-6736(11)61786-8

7. Shah, I; Ahman, E. "Unsafe abortion: global and regional incidence, trends, consequences, and challenges" (PDF). Journal of Obstetrics and Gynaecology Canada. 2009;31(12):1149-58. PMID 20085681

8. Grimes DA, Benson J, Singh S, Romero M, Ganatra B, Okonofua FE, Shah IH. Unsafe abortion: the preventable Pandemic. Journal paper, WHO. http://www.who.int/ reproductivehealth/ topics/ unsafe _abortion/article_unsafe_abortion. pdf, accessed on 14.01.2016

9. Sifris, Ronli Noa. Reproductive Freedom, Torture and International Human Rights Challenging the Masculinisation of Torture. Hoboken: Taylor and Francis. (2013) p. 3. ISBN 9781135115227.

10. Banerjee, S.K. and Tank, J. Expanding the provider base: improving access, saving lives. in: $\mathrm{R}$. Hathtootuwa, J. Tank (Eds.) Prevention of Unsafe Abortion in Asia Oceana Region. Impression Communications, New Delhi; 2009: 93-103

11. Sri Lanka, Abortion policy - The United Nations. www.un.org/esa/population/ publications /abortion/ doc/ srilanka.doc. Accessed on 14.01.2016.

12. Zaidi S, Begum F, Tank J, Chaudhury P, Yasmin H, Dissanayake M, Achievements of the FIGO Initiative for the Prevention of Unsafe Abortion and its Consequences in South-Southeast Asia. International Journal of Gynaecology and Obstetrics. 2014;126 Suppl 1:S20-3. doi: 10.1016/j.ijgo.2014.03.015.

13. Jayaratne $\mathrm{K}$, Maternal death surveillance and response (MDSR)- outcomes of 2014. http ://fhb.health.gov.lk/web/index.php?option=com_phoc adownload \& view=category\&id=40: maternal-childmorbidity-mortality-surveillance $\&$ Itemid $=150 \&$ lang $=$ en

14. Family planning association of Sri Lanka, http://www. fpasrilanka.org/index.php? option=com content\&view. Retrieved on 16.01.2016

15. de Silva DC, Jayewardene P, Hapangama A, Suraweera EG, Ranjani D, Fernando S, Karunasena C, Jinadasa S. Attitudes toward prenatal diagnosis and termination of pregnancy for genetic disorders among healthcare workers in a selected setting in Sri Lanka. Prenatal Diagnosis. 2008;28(8):715-21. doi: 10.1002/pd.2021

16. Section 363: Rape, and section 364A: Incest, penal code, Democratic Socialist Republic of Sri Lanka.

17. Boland, R.; Katzive, L. "Developments in Laws on Induced Abortion: 1998-2007". International Family
Planning Perspectives. 2008;34(3):110-120. doi:10. 1363/ifpp.34.110.08

18. Culwell KR, Vekemans M, de Silva U, Hurwitz M (July 2010). "Critical gaps in universal access to reproductive health: Contraception and prevention of unsafe abortion". International Journal of Gynecology \& Obstetrics 110: S13-16. doi:10.1016/j.ijgo. 2010.04.003

19. Olsson P, Wijewardena K. Unmarried women's decisions on pregnancy termination: Qualitative interviews in Colombo, Sri Lanka. Sexual and Reproductive Healthcare. 2010;1(4):135-41. doi: 10.1016/j.srhc.2010.07.005. Epub 2010 Aug 14.

20. Karimi M, Bonyadi M, GalehdariMr, Zareifar S. Termination of pregnancy due to Thalassemia major, Hemophilia, and Down's syndrome: the views of Iranian physicians. BMC Medical Ethics. 2008;9:19. doi: 10.1186/1472-6939-9-19PMID:19105809

21. Vasquez DN, Das Neves AV, Golubicki JL, Di Marco I, Loudet CI, Roberti JE, Palacios-Jaraquemada J, Basualdo N, Varaglia R, Vidal L. Critical care providers' opinion on unsafe abortion in Argentina. International Journal of Gynaecology and Obstetrics. 2012;116(3):249-52. doi: 10.1016/j.ijgo.2011.10.030.

22. Adamec, Ludwig. Historical Dictionary of Islam, 2nd ed. Lanham: Scarecrow Press, Inc; 2009 p. 102. ISBN 9780810861619.

23. Perera J, de Silva T, Gange H. Knowledge, behaviour and attitudes on induced abortion and family planning among Sri Lankan women seeking termination of pregnancy. Ceylon Medical Journal. 2004;49(1):14-7.

24. Henderson JT, Puri M, Blum M, Harper CC, Rana A, Gurung G, Pradhan N, Regmi K, Malla K, Sharma S, Grossman D, Bajracharya L, Satyal I, Acharya S, Lamichhane P, Darney PD. Effects of abortion legalization in Nepal, 2001-2010. PLoS One. 2013;8(5):e64775.doi:10.1371/journal.pone.0064775.

25. Benson J, Andersen K, Samandari G. Reductions in abortion-related mortality following policy reform: evidence from Romania, South Africa and Bangladesh. Reproductive Health. 2011;8:39. doi: 10.1186/1742-4755-8-39.

26. Fergusson DM, Horwood LJ, Ridder EM. Abortion in young women and subsequent mental health. Journal of Child Psychology and Psychiatry, and allied disciplines. 2006;47(1):16-24.

27. Sedgh G, Henshaw SK, Singh S, Bankole A, Drescher J. Legal abortion worldwide: incidence and recent trends. International Family Planning Perspective. 2007;33(3):106-16. 